\title{
ANÁLISE DO CONCURSO PÚBLICO COMO INSTRUMENTO DE SELEÇÃO DE PESSOAL NO SETOR PÚBLICO: PERCEPÇÃO DE UM GRUPO DE SERVIDORES DE INSTITUIÇÕES FEDERAIS DE ENSINO SUPERIOR
}

\author{
ANALYSIS OF THE PUBLIC TENDER AS STAFF RECRUITING TOOL IN \\ THE PUBLIC SECTOR: A STUDY ABOUT A GROUP OF FEDERAL \\ HIGHER EDUCATION INSTITUTIONS
}

\author{
Dartagnan Ferreira de Macêdo ${ }^{1}$, Carolina Maria Ferreira Gomes ${ }^{2}$, \\ Antonio Carlos Silva Costa ${ }^{3}$ e Andrew Beheregarai Finger ${ }^{4}$
}

Recebido em: 26/12/2015

Aprovado em: 29/06/2016

\section{RESUMO}

O presente artigo analisou o concurso público como instrumento para a seleção de pessoal no serviço público, na percepção de servidores concursados, considerando as implicações existentes para a Administração Pública e destacando os aspectos positivos e negativos e a possibilidade de aperfeiçoamento. Para tanto, realizou-se um estudo teórico-empírico, com abordagem qualitativa, por meio da análise de um grupo de servidores públicos concursados de duas Instituições Federais de Ensino Superior (IFES). Os dados coletados por meio de grupo focal e de entrevistas estruturadas foram transcritos e posteriormente interpretados mediante análise de conteúdo. Como resultados, observou-se que a estabilidade funcional dos servidores é percebida de formas diferenciadas pelos candidatos e pelas organizações e que os principais problemas em concursos públicos seriam resultantes da falta de planejamento na elaboração dos editais (que não possuem vinculação direta com a atuação prática do servidor), da pouca variedade nas avaliações e da padronização excessiva dos certames. A principal conclusão deste trabalho aponta que os concursos públicos tendem a selecionar os candidatos de acordo com a meritocracia e que esse aspecto deve ser mantido. Contudo, aprimoramentos são necessários, principalmente ampliando as fases dos processos seletivos públicos, a fim de selecionar os mais competentes candidatos para desempenharem com eficiência os serviços públicos.

Palavras-chave: Concurso Público; Seleção; Recursos Humanos; Administração Pública.

\begin{abstract}
This article analyzed the public tender as a tool for personnel to enter the public service and the existing implications for Public Administration, highlighting the positive and negative aspects and the possibility of improvement. For this, a theoretical and empirical study was used with a qualitative approach, through the analysis of a civil servants group that was approved on the public tenders of two federal institutions of higher education (IFES). The data collected by focus group and structured interviews were transcribed and later interpreted by content analysis. As a result, it was observed that the functional stability of the servers was understood in different ways by the candidates and by the organizations and the main problems result from lack of planning in the preparation of the protocols, which have no direct connection with the practical operation of the server, the little variety in the evaluations and the ratings and excessive standardization of the public tenders. The main conclusion of this paper points out that the public tenders tend to select according to merit and should be kept. However, improvements are needed, especially in expanding the phases of public tender processes to select the most competent candidates to perform public services with efficiency.
\end{abstract}

Keywords: Public Tender; Selection; Human Resources; Public Administration.

\footnotetext{
${ }^{1}$ Mestrando em Administração Pública pela Universidade Federal de Alagoas (UFAL), Brasil. E-mail: dartagnan1@outlook.com.

${ }^{2}$ Especialista em Gestão Pública Municipal pela Universidade Federal de Alagoas (UFAL), Brasil. E-mail: carolmariafg@gmail.com.

${ }^{3}$ Doutor em Psicologia pela Universidade de São Paulo (USP), Brasil. Atua como professor na Faculdade de Economia, Administração e Contabilidade da Universidade Federal de Alagoas (UFAL). E-mail: acscosta@uol.com.br.

${ }^{4}$ Doutor em Administração pela Universidade do Vale do Rio dos Sinos (UNISINOS), Brasil. Atua como professor na Faculdade de Economia, Administração e Contabilidade da Universidade Federal de Alagoas (UFAL). E-mail: finger.andrew@gmail.com.
} 


\section{Introdução}

É notório o número crescente de vagas disponibilizadas por concursos públicos no país e de interessados em ingressar no funcionalismo na busca, principalmente, da estabilidade conquistada após a aprovação. As organizações públicas esperam escolher os melhores candidatos, por meio de uma seleção baseada na meritocracia, esperando destes um perfil adequado para desempenhar as atividades do cargo.

Desde a Constituição Federal de 1988, os processos seletivos públicos foram consolidados e sua obrigatoriedade exigida para o ingresso no setor público, ressalvados os cargos em comissão. Porém, se, para alguns autores, os concursos garantem um acesso igualitário aos cargos, de forma a proporcionar às instituições públicas profissionais qualificados e competentes (MOTTA, 2011), para outros, a rigidez constitucional imposta pode ser considerada um retrocesso burocrático, pois vai de encontro à eficiência e à flexibilidade preconizadas pela Administração Pública Gerencial na reforma administrativa realizada na década de 1990 (BRESSER-PEREIRA，1996; TANIGUCHI, ARTEN, 2010).

Não há, entre os autores, um consenso acerca das vantagens ou desvantagens dos concursos públicos, apesar do reconhecimento da importância de um processo que seja pautado pelos princípios constitucionais da legalidade, impessoalidade, moralidade, publicidade e eficiência (CARVALHO FILHO, 2014). Entretanto, a aplicabilidade de alguns desses princípios é questionável, seja em relação à igualdade de oportunidades, às suspeitas de fraudes levantadas constantemente, aos editais que não observam tópicos específicos e importantes da prática profissional ou aos métodos usados nas provas realizadas pelas bancas organizadoras, que tendem a repetir editais de acordo com os certames, não considerando, muitas vezes, peculiaridades da instituição pública solicitante.

Outros aspectos relacionados à Administração de Recursos Humanos na gestão pública também devem ser considerados, pois o processo de seleção é apenas o ponto de partida que resulta na escolha dos futuros servidores públicos. Estágio probatório, avaliação periódica de desempenho, gestão por competências, treinamento e capacitação, motivação, remuneração, questões políticas e papel dos gestores e dos servidores públicos são alguns dos tópicos essenciais que precisam ser analisados dentro desse contexto (AMARAL, 2006; CAMÕES et al., 2010; NICOLAZZI, 2013; MACHADO, UMBELINO, 2001; NASSUNO, 1998).

Observa-se que as principais discussões acerca dos concursos públicos encontradas na literatura estão mais centradas no campo do Direito Administrativo. Diante disso, a principal contribuição desta pesquisa é ampliar a visão da importância dos concursos públicos para a Administração Pública, investigando a situação atual e se há algum ponto que pode ser modificado ou aprimorado para contribuir para a melhoria dos processos seletivos e, consequentemente, para a atuação dos futuros servidores públicos nos serviços prestados à sociedade. Portanto, o objetivo do presente estudo é analisar o concurso público como ferramenta de seleção de pessoal no serviço público na percepção de servidores concursados, por meio de uma pesquisa teórico-empírica realizada com um grupo de profissionais de duas Instituições Federais de Ensino Superior (IFES). Observaram-se tanto os pontos positivos quanto os negativos dos processos seletivos públicos (para os candidatos e para as organizações públicas), os possíveis problemas existentes e as implicações para a Administração Pública, além da possibilidade de adequações e aperfeiçoamentos, fazendo uma análise fundamentada na literatura sobre o tema. 
Para isso, este artigo está dividido e estruturado em cinco partes, iniciando por esta introdução. A seguir, ilustra-se uma revisão teórica acerca do tema central de estudo; discorre-se acercados procedimentos metodológicos adotados e dos principais resultados obtidos a partir da análise dos dados; e, por fim, apresentam-se as considerações finais, contendo os pontos mais relevantes deste estudo.

\section{Referencial teórico}

2.1 O profissionalismo weberiano e a meritocracia versus a Administração Pública Gerencial

A burocracia no Brasil iniciou na década de 1930, após Getúlio Vargas assumir o poder. A criação do Departamento Administrativo do Serviço Púbico (DASP), que tinha como principal objetivo modernizar a estrutura administrativa brasileira e teve inspiração no modelo Weberiano, instituiu, entre outros pontos, os concursos públicos para seleção do funcionalismo nas carreiras de Estado. Porém, a construção da burocracia nos moldes weberianos não foi consolidada no Brasil em seus aspectos mais importantes (AMARAL, 2006; MATIAS-PEREIRA, 2010). Como modelo que surgiu para combater o nepotismo e a corrupção, a burocracia não conseguiu atingir eficientemente seu papel principal, apesar de ter acarretado evolução na estrutura da máquina administrativa, com a profissionalização do serviço público, a impessoalidade, a formalidade, a legalidade e a racionalidade (BRESSER-PEREIRA, 1996).

A burocracia de Weber foi bastante disseminada nas organizações públicas em virtude do seu modelo organizacional racional-legal. As funções públicas, em consonância com o profissionalismo, devem ser exercidas por profissionais que demonstrem conhecimento e capacidade técnica, após serem submetidos a um processo competitivo justo que selecione os melhores candidatos apenas pelos seus méritos (SECCHI, 2009). Evans e Rauch (1999) argumentam que o recrutamento por meritocracia permite uma maior probabilidade de selecionar profissionais competentes, principalmente quando se garantem carreiras estruturadas, com possibilidade de progressão funcional e gratificação atrelada ao desempenho, o que poderia possibilitar maior motivação aos servidores. Nesse sentido, Freitas (2011, p. 53) destaca a relação entre os concursos e uma das características da burocracia weberiana, o profissionalismo, segundo o qual "postos chaves de uma instituição devem estar nas mãos dos melhores". Dessa forma, o concurso público seria o modo mais lícito de fazer a escolha dos mais qualificadas para ocupar esses postos.

A Constituição de 1988 buscou uma democratização e descentralização do Estado, além da profissionalização da burocracia, por meio dos concursos. Porém, com a crise do modelo burocrático, a rigidez no processo de seleção foi considerada um retrocesso, já que a ideia de Bresser-Pereira, com o Plano Diretor da Reforma do Aparelho do Estado (1995), marco da Administração Pública Gerencial no país, era de manter uma carreira estratégica para a alta burocracia e de fazer com que as demais funções fossem executadas essencialmente por terceirizados ou repassadas para a iniciativa privada (ABRUCIO, 2007; BRESSER-PEREIRA， 1996; MATIAS-PEREIRA, 2010).

Analisando a política de recursos humanos, proposta pelo Plano Diretor da Reforma do Aparelho do Estado (PDRAE) (1995), Paes de Paula (2005) confirma que a ideia central seria fortalecer a alta burocracia, por meio de seleção pública, como destacam Ferrarezi e Zimbrão (2006) em relação à formação de carreira de especialistas em Políticas Públicas e Gestão Governamental, enquanto que os "escalões inferiores" ficariam sob a responsabilidade do setor não estatal. Contudo, essa proposta tenderia 
a afetar a responsabilidade pública desse grupo, devido à ausência de uma carreira estruturada e à coexistência de grupos de servidores atuando concomitantemente pelo Regime Jurídico Único e sob o regime celetista. Assim, o entendimento do papel dos demais servidores para a cidadania poderia ser comprometido e afetar os serviços públicos executados.

Abrucio (2007) destaca que há a necessidade de uma renovação da agenda de reformas, citando quatro eixos que seriam fundamentais para a modernização do Estado brasileiro: profissionalização, eficiência, efetividade e transparência/accountability. A profissionalização da burocracia, que envolve a capacitação dos servidores públicos, é importante para a qualidade dos gestores que implementam as políticas públicas; já a eficiência, incluída como princípio constitucional após o PDRAE, é fator-chave para o sucesso dos resultados públicos, devendo existir uma atenção especial para o governo eletrônico e para a desburocratização. A efetividade, por sua vez, refere-se ao impacto proporcionado pelas ações governamentais desenvolvidas; enquanto que o aumento da transparência e da responsabilização dos agentes públicos envolve um controle efetivo dos atos praticados pelos agentes governamentais.

2.2 Concursos públicos: características, definição e marco legal

Baseando-se no caráter democrático da sociedade brasileira e no conjunto normativo atualmente em vigor no país, o concurso público como processo de seleção de pessoal apresentase como uma oportunidade de permitir que todos os cidadãos possam ter acesso a cargos e empregos públicos, preconizando um ideal de sociedade justa em consequência dessa acessibilidade em igualdade de condições (FREITAS, 2011; MOTTA, 2011).É necessário destacar a distinção entre quem ocupa cargo público, que tem vínculo estatu- tário, e o ocupante de emprego público, que possui um vínculo contratual, sob regência da CLT (Consolidação das Leis do Trabalho). Entretanto, o acesso a ambos requer aprovação em concurso público (DI PIETRO, 2014).

A realização do concurso público baseia-se em uma série de princípios constitucionais e legais que devem ser cumpridos pela administração. Segundo Di Pietro (2014), para se contratar, seja nos órgãos da Administração Direta ou Indireta, deverá se observar a Constituição Federal (1988), que determina a realização de concurso público, excetuando-se os casos previstos no inciso que dispõe sobre a contratação temporária. Ademais, alguns autores apresentam o concurso público como um princípio jurídico do Direito Administrativo, estando estabelecido constitucionalmente no artigo 37, II, com redação dada pela Emenda Constitucional no ${ }^{\circ}$ 19:

II - a investidura em cargo ou emprego público depende de aprovação prévia em concurso público de provas ou de provas e títulos, de acordo com a natureza e a complexidade do cargo ou emprego, na forma prevista em lei, ressalvadas as nomeações para cargo em comissão declarado em lei de livre nomeação e exoneração.

Amaral (2006) descreve que há diferenças significativas nos concursos tanto entre as esferas de governo (Executivo, Legislativo e Judiciário) quanto entre os entes federativos, e há uma grande diversidade de requisitos para exercer uma função pública, no que se refere à variação nos direitos e na remuneração. Essas divergências também ocorrem, possivelmente, pela falta de uma legislação específica que regulamente e normatize os concursos públicos em todo o território nacional.

Uma vez que a eficácia da maioria dos direitos constitucionais é alcançada mediante organização jurídica de condições, meios e procedimentos, o concurso público é um procedimento 
administrativo indispensável à eficácia do direito fundamental de concorrer, de forma igualitária, a um cargo ou emprego público. Esse procedimento administrativo é instaurado pelo Poder Público para selecionar impessoal e objetivamente os melhores candidatos, isto é, aqueles avaliados como mais qualificados para o provimento de cargos e empregos públicos de modo a proporcionar uma atuação estatal otimizada (CARVALHO FILHO, 2014; MOTTA, 2011).

2.3 Concurso, atribuições dos cargos e aspectos importantes da gestão de recursos humanos

O concurso público é um procedimento concorrencial, por motivar uma disputa entre candidatos, dentre os quais alguns serão favorecidos pelo resultado final mediante classificação após suas capacidades intelectual, física e/ou psíquica serem devidamente aferidas no processo seletivo. Essa avaliação de capacidades deve ser feita "de acordo com a natureza e a complexidade do cargo ou emprego" (Art. 37, II da CF). Carvalho Filho (2014, p. 633) afirma que esses são "os verdadeiros fatores que norteiam as fórmulas concursais", devendo ser respeitados na organização de qualquer certame.

A fase de planejamento das ações pela Administração na realização e no controle dos concursosdeve ser realizada com transparência, em prol do interesse público. Essa preocupação especial com tal etapa deve ser uma das providências principais para delimitar o perfil necessário que se espera dos candidatos que desempenharão as atividades na instituição, buscando uma adequação entre as atribuições do cargo ou emprego público e as atividades que serão efetivamente realizadas, além da necessidade de observar diversos outros aspectos que precisam ser considerados (MOTTA, 2011). Ainda que todos os cuidados no processo sejam realizados, não é possível garantir que apenas os melhores serão selecionados ou que as pessoas mais adequadas ingressarão no serviço público, já que muitos se submetem a alguns cargos devido ao fato de não encontrarem espaço no mercado de trabalho, e não, necessariamente, por estarem interessados verdadeiramente no cargo em disputa (ALBRECHT, KRAWULSKI, 2011; CATELAR et al., 2010).

$\mathrm{O}$ edital pode ser considerado como a lei do concurso, pois é elaborado a fim de transmitir todas as informações detalhadas acerca do certame, fixando as regras que tanto os candidatos quanto a Administração Pública deverão respeitar. $\mathrm{O}$ administrador público deve cumprir todas as normas legais em sua elaboração e observar estritamente o interesse público e a real necessidade das organizações públicas, para evitar possíveis suspeitas de irregularidades que possam ser contestadas posteriormente e para garantir o respeito aos princípios previstos na Constituição Federal (BORGES, 2009).

Carvalho Filho (2014, p. 633) ressalta, por exemplo, que "atualmente não mais é juridicamente possível o concurso apenas de títulos, porque esta forma de seleção não permite uma disputa em igualdade de condições", na medida em que as provas devem buscar aferir as competências e selecionar os melhores candidatos. Nesse sentido, a realização de um concurso com várias etapas é recomendável segundo Borges (2009), pois, como há limitações nas provas objetivas, para uma melhor mensuração das habilidades dos candidatos, seria mais eficaz a realização de um conjunto de provas. Fontainha et al. (2014), apesar de destacarem a importância do modelo dos concursos para a organização das seleções públicas no país, afirmam que é preciso avançar em novas práticas na realização desses concursos.

Alguns estudos anteriores abordaram a temática dos concursos públicos considerando diferentes perspectivas. Fontainha et al. (2015) sugerem, 
por meio de pesquisa realizada com análise quantitativa de editais de concursos, a existência de uma "ideologia concurseira" no Brasil. Já o trabalho de Nogueira (2015) registra alguns possíveis motivos e métodos para o ingresso no serviço público. Por sua vez, Leal, Silva e Dalmau (2014) analisaram as provas aplicadas aos candidatos para o cargo de Secretariado Executivo de IFES, verificando a pertinência ou não dos conteúdos abordados para o desempenho das funções do cargo.

Camões et al. (2010) observam que as organizações públicas, em geral, não vinculam a execução das atividades com o desempenho dos servidores $\mathrm{e}$, consequentemente, com a remuneração. Além disso, o foco do recrutamento e da seleção dos concursos públicos consiste nos cargos, e não nas competências, e a descrição desses cargos, por vezes genéricas demais, acaba limitando a atuação dos funcionários públicos, comprometendo a visão sistêmica, desestimulando o profissional e não atendendo verdadeiramente às necessidades específicas da organização pública.

Dessa forma, é fundamental que haja uma gestão de recursos humanos abrangente, que vá além da estruturação do recrutamento e da seleção, buscando: aperfeiçoar os servidores continuamente, realizar com eficiência a avaliação de desempenho, organizar plano de cargos, carreiras e salários que incentivem a qualificação e a produtividade baseada em uma gestão por competências, entre outros pontos que contribuam diretamente para proporcionar mais comprometimento dos servidores e, em consequência, a melhoria dos serviços prestados pela gestão pública (AMARAL, 2006; TANIGUCHI, ARTEN, 2010; CAMÕES et al., 2010; NICOLAZZI, 2013; CALDAS, 2011).

\section{Método}

O presente estudo relata uma pesquisa exploratória, baseada no levantamento das informações acerca de uma temática que possui poucos estudos anteriores, especialmente no campo da gestão pública: os concursos públicos. A abordagem qualitativa permitiu, por meio de registro e posterior análise dos dados, um aprofundamento e uma riqueza das respostas, bem como uma interpretação com base em conhecimentos teórico-empíricos (SEVERINO, 2007; VIEIRA, ZOUAIN, 2006).

$\mathrm{O}$ estudo foi realizado entre os meses de dezembro de 2014 e janeiro de 2015 , com uma amostra não probabilística, em que os participantes foram selecionados intencionalmente, por tratar-se de um grupo homogêneo, que atendia aos objetivos da pesquisa, de acordo com critérios de acessibilidade e disponibilidade. Os pesquisados foram oito servidores públicos federais, vinculados a duas IFES do estado de Alagoas, sendo quatro servidores de cada IFES (IF A e IF B). O quadro1, exposto a seguir, ilustra o perfil dos participantes da pesquisa. 


\begin{tabular}{|c|c|c|c|c|}
\hline Participante & Sexo & Idade & Cargo & IFES \\
\hline P1 & M & 26 & $\begin{array}{c}\text { Assistente } \\
\text { Administrativo }\end{array}$ & IF A \\
\hline P2 & M & 29 & Administrador & IF A \\
\hline P3 & M & 31 & Contador & IF B \\
\hline P4 & M & 28 & Contador & IF A \\
\hline P5 & F & 27 & Administradora & IF B \\
\hline P6 & F & 24 & $\begin{array}{c}\text { Assistente } \\
\text { Administrativo }\end{array}$ & IF B \\
\hline P7 & M & 29 & $\begin{array}{c}\text { Assistente } \\
\text { Administrativo }\end{array}$ & IF A \\
\hline P8 & M & 42 & $\begin{array}{c}\text { Técnico em Tecnolo- } \\
\text { gia da Informação }\end{array}$ & IF B \\
\hline
\end{tabular}

Quadro 1 - Perfil dos participantes da pesquisa.

Fonte: elaborado pelos autores.

Os instrumentos de coleta de dados foram fundamentados na pesquisa bibliográfica realizada, sendo utilizados grupo focal, entrevistas estruturadas e análise documental. É importante destacar que os resultados e as discussões desta pesquisa são limitados aos métodos adotados e às percepções dos sujeitos pesquisados.

O grupo focal permite ao pesquisador observar uma quantidade de dados significativa a respeito de determinado tema, por meio da interação entre os participantes, gerando uma pluralidade de ideias e argumentos (MORGAN, 1997). O grupo teve duração de uma hora e dezessete minutos e foi direcionado por um dos pesquisadores por meio de um roteiro elaborado previamente, realizando o mínimo de interferência nas discussões, apenas para evitar a fuga das respostas ao tema central da pesquisa.

De forma a complementar os dados e enriquecer a pesquisa, realizaramse com os participantes do grupo oito entrevistas estruturadas, que, segundo Severino (2007, p.125), "são aquelas em que as questões são direcionadas e previamente estabelecidas [...] aproxima-se mais do questionário, embora sem a impessoalidade deste". Além dis- so, foi feita uma análise documental dos editais utilizados para ingresso nos cargos atuais dos servidores públicos que participaram desta pesquisa, objetivando analisar os conteúdos programáticos e a descrição dos cargos.

Posteriormente, todos os dados foram transcritos, organizados, categorizados e codificados para possibilitar posterior triangulação e análise. O método de análise de dados utilizado foi a análise de conteúdo, baseado em Bardin (2010), que permite descrever os conteúdos das mensagens e interpretá-los, a fim de observar os aspectos e as informações mais importantes.

\section{Apresentação e discussão dos resul- tados}

Os participantes deste estudo são servidores públicos concursados vinculados a duas IFES do estado de Alagoas, os quais ocupam os seguintes cargos: administrador, contador, assistente em administração e técnico em Tecnologia da Informação (TI). A idade média é de 29 anos, sendo seis participantes do sexo masculino e dois do sexo feminino. Todos possuem grande experiência na realização de provas de concursos, 
pois, em média, cada um participou de 19 processos seletivos. Quanto à preparação em termos de tempo dedicado aos estudos, foi consenso que o grau de esforço varia bastante, ressaltandose, porém, que, para os cargos atuais, a maioria necessitou de uma dedicação maior para obter aprovação. Os fatores que influenciariam a aprovação, além do tempo dedicado aos estudos, seriam a realização de provas constantemente, a sorte e o desenvolvimento de métodos de estudo condizentes com o padrão das questões elaboradas pela banca organizadora do certame.

Observa-se uma expansão do quantitativo de vagas ofertadas e do mercado de produtos e serviços relacionados aos concursos, bem como um interesse crescente em tornar-se servidor público manifestado por uma parcela da população (FREIRE et al., 2012; FONTAINHA et al., 2015). A maior parte do círculo social dos participantes já realizou concursos, o que confirma essa tendência. Segundo os respondentes, esse fato teria se tornado um aspecto cultural, principalmente na região Nordeste, pois as oportunidades de empregabilidade no setor privado seriam escassas e o salário médio no setor público seria relativamente melhorem relação às empresas privadas, na maioria dos cargos. No que se refere às motivações principais para desempenhar uma função no setor público, as respostas principais foram a conquista de independência, se- gurança e estabilidade financeira, além da oportunidade profissional de acessara carreira que o indivíduo almeja.

Nesse sentido, um tópico interessante que entrou em discussão no grupo foi aprática de os candidatos iniciarem por concursos de menor porte, com cargos e salários menos atrativos, em virtude da necessidade de acumular recursos financeiros para a manutenção dos estudos, que possuem custos elevados, para, posteriormente, realizarem uma preparação para a função que realmente almejam. Nesse contexto, os estudantes geralmente fazem uso de cursos preparatórios, em que a metodologia de ensino, a qualidade técnica e o material utilizado estão entre os fatores mais importantes. Porém, ressalta-se que condições socioeconômicas como, por exemplo, renda familiar, grau de escolaridade acima do ensino médio e ter estudado em escola privada resultariam em uma maior probabilidade de aprovação, caracterizando uma desigualdade entre os candidatos (ANDRADE, ALBUQUERQUE, 2012; CASTELAR et al., 2009).

4.1 Aspectos positivos e negativos na visão dos candidatos e das organizações públicas

O quadro 2, apresentado a seguir, demonstra alguns dos principais resultados obtidos por meio da análise dos dados obtidos durante as discussões realizadas no grupo focal. 


\begin{tabular}{|c|c|c|c|}
\hline Categorias & Subcategorias & Temas & Exemplos de verbalizações \\
\hline \multirow{4}{*}{$\begin{array}{c}\text { Aspectos } \\
\text { positivos dos } \\
\text { concursos } \\
\text { públicos }\end{array}$} & \multirow[t]{2}{*}{$\begin{array}{l}\text { Visão dos } \\
\text { candidatos }\end{array}$} & Estabilidade & $\begin{array}{l}\text { “A estabilidade, em ordem de prioridade, é } \\
\text { primeiro lugar [...] na empresa privada, por } \\
\text { mais que você faça carreira maravilhosa lá, } \\
\text { pode acontecer o que aconteceu com a minha } \\
\text { família, por exemplo, que, de uma hora para } \\
\text { outra, fizeram um corte de gastos, e não con- } \\
\text { sideraram os } 16 \text { anos de empresa, e de hoje } \\
\text { para amanhã você não tem mais emprego. E a } \\
\text { sua família? Acho que a estabilidade é tudo”. }\end{array}$ \\
\hline & & $\begin{array}{c}\text { Flexibilidade } \\
\text { de horários }\end{array}$ & $\begin{array}{l}\text { "Para mim é a flexibilidade de horários o } \\
\text { mais importante”. } \\
\text { "Tenho mais tempo para estudar". }\end{array}$ \\
\hline & \multirow[b]{2}{*}{$\begin{array}{l}\text { Visão das } \\
\text { organizações } \\
\text { públicas }\end{array}$} & Meritocracia & $\begin{array}{l}\text { "As organizações acabam selecionando pro- } \\
\text { fissionais melhores, a priori". } \\
\text { "Ser aprovado na primeira fase, que é uma } \\
\text { prova objetiva, é meritocracia para quem } \\
\text { sabe do assunto". }\end{array}$ \\
\hline & & $\begin{array}{c}\text { Profissionaliza- } \\
\text { ção da gestão } \\
\text { pública }\end{array}$ & $\begin{array}{l}\text { “É o melhor método para as organizações } \\
\text { pela impessoalidade, porque no serviço pú- } \\
\text { blico o critério político é muito forte, então } \\
\text { se você for fazer uma seleção como se faz no } \\
\text { serviço privado, não vai dar certo, porque } \\
\text { dentro da Administração Pública brasileira, } \\
\text { o patrimonialismo ainda é visível”. }\end{array}$ \\
\hline \multirow{4}{*}{$\begin{array}{l}\text { Aspectos ne- } \\
\text { gativos dos } \\
\text { concursos } \\
\text { públicos }\end{array}$} & \multirow{2}{*}{$\begin{array}{l}\text { Visão dos } \\
\text { candidatos }\end{array}$} & Desmotivação & $\begin{array}{l}\text { "A acomodação é uma realidade. Alguns pas- } \\
\text { sam em um [concurso], até poderiam ter po- } \\
\text { tencial para algo a mais, mas se acomodam, } \\
\text { não desenvolvem suas capacidades, ficando } \\
\text { desmotivados [...]". }\end{array}$ \\
\hline & & $\begin{array}{c}\text { Estrutura } \\
\text { organizacional } \\
\text { burocratizada }\end{array}$ & $\begin{array}{l}\text { “[...] sempre é uma estrutura muito buro- } \\
\text { crática, não existe muita oportunidade de se } \\
\text { criar, de se desenvolver alguma coisa nova, } \\
\text { termina desmotivando [...]”. }\end{array}$ \\
\hline & \multirow[b]{2}{*}{$\begin{array}{l}\text { Visão das } \\
\text { organizações } \\
\text { públicas }\end{array}$} & Estabilidade & $\begin{array}{l}\text { "Pela estabilidade, acho que também há uma } \\
\text { dificuldade de tirar um mau funcionário, ou } \\
\text { seja, talvez a empresa tenha alguns funcioná- } \\
\text { rios que gostaria de demitir, se não fosse por } \\
\text { concurso". }\end{array}$ \\
\hline & & $\begin{array}{l}\text { Servidores não } \\
\text { comprometidos }\end{array}$ & $\begin{array}{l}\text { “Existem pessoas que fazem concursos uni- } \\
\text { camente para 'pular' para um próximo con- } \\
\text { curso [...] vários casos de pessoas que passa- } \\
\text { ram no concurso, entram em um setor, e logo } \\
\text { são transferidas, porque passavam o tempo } \\
\text { todo estudando [...] até que conseguir passar } \\
\text { em outro concurso [...]". }\end{array}$ \\
\hline
\end{tabular}

Quadro 2 - Aspectos positivos e negativos dos concursos públicos para os candidatos e para as organizações públicas apontados no grupo focal.

Fonte: elaborado pelos autores. 
Observa-se que a estabilidade adquirida pelos servidores públicos, após o período de estágio probatório, foi considerada o principal atrativo para os candidatos. Relatos de experiências familiares de demissões no setor privado, mesmo após décadas de serviços prestados, demonstram um fator de caráter socioeconômico e emocional que pode interferir na escolha pela carreira pública, indo ao encontro de alguns pontos também registrados no trabalho de Nogueira (2015). Possibilitar uma maior segurança para a família foi outro ponto apresentado, seguindo a mesma tendência relatada anteriormente.

A flexibilidade de horários, apesar da ressalva de que tal característica dependerá do órgão de lotação ou do fato de ser uma empresa da administração direta ou indireta, foi bastante citada, principalmente quando comparada com a iniciativa privada. Nesse ponto, há uma relação direta entre o regime de trabalho e a questão da flexibilidade. No regime estatutário, em que os servidores possuem estabilidade funcional, esse aspecto seria bastante valorizado; já em uma instituição cujas relações trabalhistas são ditadas pela Consolidação das Leis do Trabalho (CLT), os horários de trabalho aproximamse daqueles praticados em organizações que buscam o lucro e que, consequentemente, seriam mais exigentes.

Esse paralelo entre o setor público e o setor privado acarretou diversas ponderações acerca das diferenças entre os tipos de organização. O fator apontado como vantagem do setor público consistiu nos benefícios proporcionados, com ênfase na estabilidade e no menor grau de exigência. Nas empresas privadas, o principal aspecto negativo seria a pressão excessiva por resultados e produtividade. Cunha e Cavalcanti (2012) acrescentam que o processo de recrutamento e seleção em ambos os setores é bastante complexo, mas que, no setor público, alguns fatores que se referem a aptidões dos indivíduos não podem ser identificados apenas na prova realizada, o que seria um diferencial positivo para as organizações privadas.
Ainda em relação às semelhanças e diferenças entre os setores público e privado, a gestão por competências é descrita como algo interessante para os profissionais, embora seja bem mais desenvolvida nas organizações privadas. No tocante à gestão de pessoas, de acordo com Amaral (2006), a gestão por competências tem uma influência positiva, interferindo na seleção, alocação, capacitação e avaliação de desempenho; contudo, ainda não são apresentados muitos exemplos concretos na literatura acerca da aplicabilidade desta última no setor público, constituindo, por isso, um campo a ser desenvolvido. Um estudo realizado por Nicolazzi (2013) apontou que servidores de uma Universidade Federal observaram diversas vantagens nesse modelo de gestão de pessoas, principalmente no que diz respeito a uma melhoria na frequência e qualidade das capacitações, o que vai ao encontro das opiniões dos servidores das duas Instituições Federais objetos desta pesquisa.

Como aspecto negativo, a desmotivação em longo prazo foi o ponto mais enfatizado pela maioria, sendo, portanto, uma característica que deve ser observada pelos gestores públicos. Um servidor desmotivado não cumprirá suas atividades da melhor forma possível, prejudicando o bom andamento dos serviços da instituição. A estrutura organizacional das Instituições Federais foi considerada engessada e com características predominantemente burocráticas, com decisões muito centralizadas, havendo pouco espaço para inovação, criatividade e autonomia de atuação do servidor. Também foi citada a tendência de acomodação, considerada um aspecto negativo porque limitaria a possibilidade de crescimento e desenvolvimento do potencial dos indivíduos. Nesse contexto, Matias-Pereira (2010) aponta a centralização e a verticalização das decisões e a falta de flexibilidade, com preocupação exacerbada com as regras, como as duas principais disfunções da burocracia, que desvirtuam o conceito e a noção de eficiência incialmente prevista por Weber. 
Outros dois pontos levantados foram a dificuldade de ascensão e progressão na carreira, devido à impossibilidade de mudança de cargo, excetuando-se a possibilidade de assumir cargos de chefia em comissão, e a existência de concursos realizados apenas para cadastro de reserva, que não obrigam as organizações a nomearem os candidatos, gerando frustações e desconfianças. A existência desse cadastro de candidatos pode ser de interesse público, segundo Motta (2011), se for realizado de forma planejada com o intuito de possibilitar a nomeação dos profissionais em caso de necessidade da Administração. Porém, realizar concursos sem disponibilizar vagas, apenas para formar um cadastro, é algo bastante questionável. Uma lei geral dos concursos, que tramita no Congresso Nacional, proíbe essa opção e disciplina uma série de regras importantes para a normatização dos concursos públicos, caracterizando, se aprovada, um importante instrumento para a segurança de candidatos e organizações públicas.

Analisando as vantagens da realização de concursos, sob o ponto de vista das organizações públicas, a meritocracia foi o aspecto considerado como mais importante. A escolha dos candidatos por meio de uma seleção pública efetuada mediante critérios delimitados previamente em edital permitiria uma seleção impessoal e baseada nos méritos dos candidatos (MOTTA, 2011; FREITAS, 2011; DI PIETRO, 2014). A priori, haveria a seleção dos melhores profissionais que demonstraram interesse no cargo específico e, consequentemente, uma maior qualificação do quadro funcional. Porém, essa afirmativa não pode ser considerada uma verdade absoluta, pois nem sempre haveria o real interesse do candidato em atuar no cargo em disputa.

A busca pela profissionalização da gestão pública e pela eliminação das práticas patrimonialistas e da troca de favores na seleção de pessoal, ainda bastante comum entre cargos comissionados, foi outro ponto destacado como uma vantagem da seleção baseada no- mérito. Também foi citada a relativa facilidade da utilização dos concursos públicos para realizar a seleção de pessoal e a consolidação do processo no país.

Por sua vez, em relação aos aspectos negativos dos concursos para as organizações da Administração Pública e, consequentemente, para a sociedade, observou-se que, curiosamente, a discussão resultou em um dos tópicos mais debatidos durante o grupo focal e que gerou diversas opiniões, muitas vezes discordantes entre os participantes. Apesar de afirmarem que a estabilidade seria o fator mais importante para os candidatos, tal fator também seria o principal ponto negativo para as organizações públicas, o que demonstra certo paradoxo. Uma analogia com as empresas privadas demonstra maior facilidade no processo de demissão de colaboradores ineficientes, o que não ocorre no setor público, em que, após a estabilidade, os servidores só podem ser exonerados em determinados casos previstos em lei.

Essa questão da estabilidade dos servidores, bastante polêmica, já foi discutida por diversos autores. Por um lado, há argumentos de que um dispositivo constitucional que permita a demissão por desempenho insuficiente poderia contribuir para uma melhor administração de pessoal pelos gestores públicos, de forma a consolidar o Gerencialismo (NASSUNO, 1998); por outro lado, mesmo com a Constituição Federal e com a Lei n. ${ }^{\circ} 8.112 / 90$ assegurando a punição do servidor em determinados casos, é preciso que se considere que a estabilidade representa uma preservação de autonomia para o servidor, em relação à descontinuidade do serviço público após mudanças no ambiente político, devendo a eficiência dos servidores ser assegurada pelo desenvolvimento constante, por meio da adoção de políticas de capacitação continuada (CALDAS, 2011).

Assim, esse confronto entre a relativa dificuldade de demissão e o aparente "privilégio" da estabilidade em conjunto com a proteção do servidor contra retaliações políticas, interesses clientelistas 
e demissões arbitrárias deve ser considerado, garantindo o direito à ampla defesa (MACHADO; UMBELINO, 2001). Nesse sentido, Amaral (2006) pondera que as relações de poder presentes na política interferem na ineficiência da máquina pública. Uma das dificuldades de exonerar um mau funcionário estaria mais relacionada à avaliação de desempenho ineficiente do que propriamente ao processo seletivo. Mesmo não sendo o objetivo principal deste trabalho, a análise do processo de avaliação de desempenho nas organizações públicas é primordial, conforme Machado e Umbelino (2001) explicam, visando à eficiência dos serviços públicos.

Observou-se, ainda, que muitos candidatos realizam concurso para os níveis fundamental ou médio, mesmo após graduados. Nesses casos, a necessidade financeira do indivíduo seria o fator principal, como também observaram Albrecht e Krawulski (2011). Já de acordo com Castelar et al. (2010, p. 92), essa situação "aponta para uma alocação ineficiente dos recursos públicos conjugada a uma falha estrutural do mercado de trabalho e do sistema de ensino regional", fato coerente com o que se observa no contexto socioeconômico. Outras questões foram apontadas como, por exemplo, trabalhar em um cargo para o qual não se tem aptidão, apenas pelo fator financeiro e pela estabilidade.

O tempo de processamento de todo o certame público foi citado como um possível entrave para alguns órgãos públicos com carência de servidores e urgência na convocação. Ainda nesse contexto, o prazo de validade dos concursos pode se tornar um problema às organizações quando há um lapso temporal grande entre os processos de seleção, o que pode acabar gerando um engessamento do quadro funcional $e$ atrasando a reposição de servidores ou a criação de novas vagas em razão de ampliação das instituições, fato comum entre IFES, que nos últimos anos ampliaram de forma constante seus campi.

\subsection{Problemas identificados}

Neste tópico da análise, procurou-se identificar quais os principais problemas no que se refere à seleção de pessoal por meio dos concursos públicos. Para isso, realizou-se uma análise dos editais dos concursos em que os servidores das duas Instituições Federais de Ensino foram aprovados, observando principalmente os conteúdos programáticos e a descrição dos cargos, a fim de fazer uma triangulação entre os dados coletados nos documentos, nas entrevistas e no grupo focal. A partir dessas análises, foram identificados três problemas principais: inadequação do conteúdo e das atividades previstas em edital ao que efetivamente é executado pelos servidores; falhas na gestão de recursos humanos das instituições públicas; e padronização das provas dos concursos públicos, o que gera um processo seletivo deficitário.

Os conteúdos das provas, previstos nos editais, foram compostos das seguintes disciplinas: língua portugue$\mathrm{sa}$, informática, fundamentos de Administração Pública e conhecimentos específicos para cada cargo. Um dos editais testou também o conhecimento em raciocínio lógico, e outro avaliou a legislação aplicada à IFES. O edital, segundo Fontainha et al. (2015), é o instrumento de recrutamento e seleção construído com o intuito de escolher e legitimar os servidores estatais.

Ressalta-se que houve uma padronização em relação aos conteúdos dos editais analisados, especificamente nos conhecimentos específicos, em que foram abordados alguns conteúdos bastante genéricos. Os entrevistados corroboraram essa generalização, mas afirmaram que o conteúdo cobrado foi amplamente abordado na prova, dentro do que estava previsto em edital. Contudo, quando questionados sobre a aplicabilidade dos conhecimentos exigidos para ingresso no cargo público em relação às atividades cotidianas do cargo, a 
maioria afirmou que não existe relação direta ou que, quando existe, é de maneira muito superficial.

Essa deficiência não estaria relacionada apenas ao processo de seleção, segundo os respondentes, mas também à falta de planejamento na distribuição das vagas pela instituição que recebe os profissionais, acarretando uma dificuldade de adequação ao setor de lotação para alguns servidores e uma dificuldade para a instituição encontrar um perfil adequado às necessidades do cargo apenas por meio do processo seletivo nos moldes atuais. Essas fragilidades seriam mais frequentes quando a avaliação é realizada apenas por meio de prova objetiva, descrita como insuficiente.

Observou-se, ainda, que a descrição das atribuições dos cargos nos editais foi exatamente a mesma para as duas Instituições de Ensino, mesmo considerando o lapso temporal de cinco anos entre os concursos (2006 a 2011). Além disso, as atribuições são genéricas em alguns cargos, descrevendo as atividades que serão desempenhadas e outras correlatas. A possibilidade de a banca organizadora ter sido a mesma pode ter influenciado nessa padronização, o que pode demonstrar uma articulação pouco eficiente entre as bancas e as IFES no que concerne ao planejamento e à elaboração das especificidades dos editais.

Os resultados registrados estão em consonância com o estudo de Leal, Silva e Dalmau (2014), que, ao analisarem os instrumentos de seleção, especificamente para o cargo de secretariado executivo de IFES, registraram que as questões elaboradas pelas bancas não estariam totalmente de acordo com a descrição do cargo e com os conhecimentos necessários para o bom desempenho das funções do profissional, além de não permitirem a avaliação comportamental e de habilidades.

Outro ponto a ser destacado refere-se às diferenças entre as opiniões dos servidores de nível médio e dos servidores graduados, havendo um padrão em relação à satisfação com as atividades desempenhadas e com o que era esperado de acordo com o previsto em edital. Enquanto os servidores dos cargos de nível médio afirmaram que não há relação direta entre conteúdo e atribuições, enfatizando que exercem atividades além das previstas em edital, a maioria dos servidores de cargos de nível superior, particularmente os administradores, demonstraram que as atribuições também não possuem ligação efetiva, mas, no geral, estão aquém do esperado por eles, e que a satisfação acontece muito mais pelo ambiente de trabalho do que pelas atividades executadas. $\mathrm{O}$ enriquecimento do trabalho, job enrichment, poderia, assim, ser considerado pelos gestores visando motivar esses servidores.

O papel desempenhado pela gestão de recursos humanos das Instituições foi outro problema apontado. É imprescindível que o gestor de cada departamento saiba exatamente qual o perfil de profissional que o setor necessita, de forma a moldar o processo seletivo de acordo com essa necessidade. Porém, observou-se uma desconexão entre esses pontos. A organização, portanto, nem sempre estaria preparada para receber o servidor, pois não haveria um mapeamento dos processos e das atribuições requeridas nem uma clareza na transparência e missão das tarefas. A qualificação gerencial das chefias consistiria em um dos pontos mais importantes a ser observado, conjuntamente com a revisão do processo de avaliação de desempenho periódico do servidor público, a fim de garantir um aprimoramento baseado na produtividade e na qualidade dos serviços prestados, visando à eficiência da gestão pública (MACHADO; UMBELINO, 2001).

A metodologia de seleção dos concursos seria muito mecanizada, no sentido de exigir o mesmo padrão para cargos e instituições diferentes, aferindo apenas os conhecimentos acerca daqueles tópicos selecionados pela banca organizadora ou aferindo conhecimentos 
obtidos por meio de técnicas de estudo específicas para cada perfil da banca, o que, na prática, não caracteriza verdadeiramente conhecimento daqueles conteúdos. Ademais, uma prova apenas objetiva, com alternativas de múltipla escolha, mede parcialmente os conhecimentos dos candidatos, de modo que aspectos como atitudes e comportamentos, indispensáveis para verificar as aptidões dos mesmos, são ignorados (FONTAINHA et al., 2014).

A questão da padronização dos processos seletivos foi sugerida, inicialmente, como algo positivo, para evitar desconformidades e critérios arbitrários nas seleções. Entretanto, após o andamento das discussões, chegou-se a um consenso de que padronizar demasiadamente seria na verdade um problema, pois não se observariam as especificidades de cada órgão, o que tornaria os concursos ainda mais mecânicos, e não se mensurariam as necessidades das organizações. Como já descrito, nem sempre as atribuições desempenhadas correspondem ao que estava previsto anteriormente em edital, o que pode acarretar problemas posteriores.

\subsection{Sugestões de aperfeiçoamento}

De acordo com as informações obtidas pelo conjunto de dados coletados, foi possível destacar algumas sugestões apresentadas. $\mathrm{O}$ quadro 3 , a seguir, apresenta um resumo das principais ideias expostas, evidenciando que os todos respondentes aprovam os concursos públicos como ferramenta de seleção de pessoal no serviço público, embora ressaltem a necessidade de ajustes, a fim de que os melhores profissionais sejam selecionados.

\begin{tabular}{|c|c|c|}
\hline Categoria & Temas & Exemplos de verbalizações \\
\hline \multirow{8}{*}{$\begin{array}{l}\text { Aperfei- } \\
\text { çoamento } \\
\text { dos proces- } \\
\text { sos } \\
\text { seletivos } \\
\text { públicos }\end{array}$} & \multirow{4}{*}{$\begin{array}{l}\text { Mudança na } \\
\text { metodologia } \\
\text { de seleção/ } \\
\text { avaliação }\end{array}$} & $\begin{array}{l}\text { "O processo de seleção deveria ser analisado com mais cuidado desde a defi- } \\
\text { nição das necessidades de pessoal, de forma a determinar exatamente o que se } \\
\text { espera dos futuros servidores para que as avaliações, sendo teóricas ou práti- } \\
\text { cas, avaliem os candidatos no que é essencial para suas futuras atribuições". }\end{array}$ \\
\hline & & $\begin{array}{l}\text { "A prova prática sempre é pertinente, pois nela o candidato terá maior } \\
\text { contato com as atividades que irá desempenhar, e a instituiçâo também } \\
\text { conhecerá melhor os conhecimentos práticos do candidato". }\end{array}$ \\
\hline & & $\begin{array}{l}\text { "Pensando no critério da meritocracia, o processo de seleção dos con- } \\
\text { cursos é parcialmente adequado. O que precisaria de um ajuste é que } \\
\text { as provas objetivas sejam mais centradas especificamente nos cargos em } \\
\text { disputa e que toda prova de concurso tenha uma etapa prática que pro- } \\
\text { cure avaliar tanto conhecimentos que serão utilizados no dia a dia como } \\
\text { habilidades pessoais necessárias ao cargo". }\end{array}$ \\
\hline & & $\begin{array}{l}\text { "Os concursos deveriam ter mais etapas práticas e de avaliação de com- } \\
\text { petências". }\end{array}$ \\
\hline & \multirow{2}{*}{$\begin{array}{l}\text { Adequação } \\
\text { do edital } \\
\text { ao cargo }\end{array}$} & $\begin{array}{l}\text { "O conteúdo programático deveria ser mais direcionado à atividade que } \\
\text { realmente será exercida pelo servidor em potencial, o que é uma falha da } \\
\text { maioria dos concursos". }\end{array}$ \\
\hline & & "O edital deveria ser o mais especifico para cada cargo e função". \\
\hline & \multirow{2}{*}{$\begin{array}{l}\text { Papel dos } \\
\text { gestores } \\
\text { das orga- } \\
\text { nizações } \\
\text { públicas }\end{array}$} & $\begin{array}{l}\text { "Os gestores de recursos humanos das organizações deveriam mapear as } \\
\text { necessidades dos setores que demandam as pessoas, de forma a compor os } \\
\text { perfis dos programas das provas. Assim, existiria a possibilidade de uma pro- } \\
\text { va prática ou análise de caso como meios deseleção". }\end{array}$ \\
\hline & & $\begin{array}{l}\text { "As seleções por prova objetivas elou de títulos só medem a capacidade de ra- } \\
\text { ciocinio, aprendizagem e conhecimentos dos inscritos. No entanto, as habilidades } \\
\text { interpessoais e aptidões não são analisadas. No caso de funcionários que tenham } \\
\text { mais de uma opção de lotação, é importante ser analisado o perfil de cada servi- } \\
\text { dor para que sua lotação seja compativel com seu perfil". }\end{array}$ \\
\hline
\end{tabular}

Quadro 3 - Sugestões de aperfeiçoamento expostas pelos servidores nas entrevistas.

Fonte: elaborado pelos autores. 
Considerando que menos de $50 \%$ dos servidores pesquisados realizaram prova prática e que as etapas de seleção contribuíram superficialmente para o desempenho das atividades laborais dos respondentes, pode-se observar a preocupação dos servidores quanto à necessidade de uma etapa que abarque mais aspectos práticos e que seja condizente com as atividades que serão desempenhadas. Também é possível visualizar sugestões que têm relação direta com os setores de gestão de pessoas das organizações públicas (que requisitam os profissionais), com o conteúdo programático e com as atribuições previstas nos editais, que precisam ser mais próximas da realidade dos cargos, aspecto este também registrado na pesquisa de Leal, Silva e Dalmau (2014).

Pode-se destacar que realizar várias fases em um concurso por meio de uma extensão do processo seria, para a maioria, uma forma de melhorar as seleções. A possibilidade de modificações, dentro desse contexto, parece algo factível, sendo fundamental, para isso, uma atuação mais direta das organizações públicas na escolha dos métodos de seleção mais adequados para as suas necessidades, contemplando um planejamento eficiente dos recursos humanos e compartilhando responsabilidades com as bancas organizadoras. Em relação a um concurso com várias fases, que seria o mais recomendável, visto que analisaria o candidato de forma mais holística, os participantes citaram alguns exemplos do que poderia ser solicitado, tais como prova objetiva, física, de títulos, prática e oral, avaliação psicológica, exame psicotécnico, análise de experiências anteriores e realização de curso de formação, de acordo com cada cargo, como também é sugerido por Borges (2009).

Alguns concursos para cargos específicos já requerem uma avaliação mais completa, como, por exemplo, para policiais, professores, juízes e diplomatas. Uma avaliação de comporta- mentos e atitudes, isto é, uma avaliação mais qualitativa, também seria uma possibilidade de aperfeiçoamento que permitiria medir aspectos importantes dos indivíduos.Entretanto, dois pontos devem ser levados em consideração. Primeiramente, para evitar uma subjetividade que possa ensejar possíveis fraudes ou favorecimentos, todas as etapas e a sistemática de avaliação devem estar previstas detalhadamente em edital e serem pautadas pelos princípios constitucionais. Em segundo lugar, uma avaliação de títulos ou experiências anteriores deve ser apenas classificatória, pois, apesar de ser um incentivo à formação continuada do servidor e evidenciar dedicação em adquirir conhecimentos por parte do candidato, tendem a ser injustas com os candidatos recémformados ou menos experientes.

Um processo menos padronizado, com mais fases, resultaria em um aumento de custos financeiros considerável aos processos seletivos. Porém, também deve ser questionado o que seria mais oneroso: os custos financeiros para a realização do processo ou o custo intangível de selecionar não necessariamente os melhores candidatos, podendo gerar altos índices de absenteísmo, rotatividade nos cargos, desmotivação e, consequentemente, ineficácia nos serviços prestados.

Um levantamento constante do quantitativo e da necessidade de vagas para cada área da instituição, mediante a realização de concursos mais frequentes e de acordo com a real necessidade, seria indispensável. Observa-se que houve uma evolução a partir da Constituição de 1988, principalmente nos últimos anos, tanto em termos de quantidade de vagas quanto na qualidade dos novos servidores. A Administração Pública brasileira, entretanto, ainda convive com algumas características patrimonialistas e burocráticas, ficando os fundamentos da Administração Pública Gerencial restritos a alguns exemplos positivos isolados no país, o que 
compromete a qualidade dos serviços públicos, apesar dos inegáveis avanços.

Outros tópicos apontados como sugestões foram citados: corrigir as deficiências existentes na avaliação do estágio probatório e nas avaliações periódicas de desempenho, estruturar as carreiras, possibilitar uma flexibilização da estabilidade, adotar a gestão por competências, aderir à remuneração baseada em produtividade, realizar treinamentos constantes para aprimoramento e qualificação do pessoal, estabelecer relações mais próximas com os sindicatos e os representantes das categorias profissionais e equalizar a discrepância dos salários entre instituições e entes federativos diferentes por meio de equiparação salarial. Mesmo que muitas dessas ideias não tenham relação direta com os concursos públicos e que algumas sejam questionáveis, esses argumentos são importantes para compreender as demandas e os discursos de um grupo de servidores públicos concursados.

\section{Considerações finais}

O objetivo principal deste estudo foi ampliar a discussão acerca dos concursos públicos como método de seleção de pessoal no serviço público, na percepção de um grupo de servidores concursados vinculados a duas IFES. Foram apontadas as vantagens e desvantagens do ponto de vista dos candidatos e das organizações públicas, os problemas considerados pelos sujeitos da pesquisa e algumas possíveis soluções para aperfeiçoar o processo.

Contatou-se que todos os participantes da pesquisa são a favor do concurso público, considerando-o já consolidado no país, desde a Constituição Federal de 1988, tanto que há uma demanda crescente de candidatos interessados em se tornarem funcionários públicos. Porém, também foi consenso que há a necessidade de aperfeiçoamento nos processos seletivos públicos, para que a Administração Pública efetivamente selecione os melhores servidores para ocupar as funções públicas.

Os aspectos positivos citados mais relevantes foram a estabilidade, para os postulantes aos cargos, e a seleção baseada na meritocracia, para as organizações públicas. Já entre os pontos negativos, destacaram-se a tendência à desmotivação e à acomodação, para os futuros servidores, e a estabilidade funcional dos servidores, para a Administração Pública. Percebe-se, nesse sentido, que há uma polêmica em relação à estabilidade, pois esta poderia ser um fator prejudicial para o desempenho dos servidores. Uma avaliação de desempenho eficaz e uma gestão de pessoas por competências que atrele remuneração ao desempenho e à produtividade poderiam ser soluções mais globais. É imprescindível, também, que haja uma política de capacitações permanente, para garantir o desenvolvimento contínuo dos servidores.

As organizações públicas foram descritas como muito burocratizadas, carecendo de mais eficiência e de características do Gerencialismo, pois a estrutura organizacional atual prejudica o bom desempenho das atividades. $\mathrm{Ob}$ servou-se que os três problemas principais identificados por meio da análise realizada foram: incompatibilidade entre os conteúdos programáticos e as descrições dos cargos com as atividades realizadas; falha nos processos de recursos humanos das instituições públicas; e provas excessivamente padronizadas e com apenas uma fase, o que impossibilita uma avaliação completa das competências dos indivíduos.

Como sugestões de aperfeiçoamento, diversos pontos foram abordados, incluindo a ampliação das fases dos processos seletivos, de forma a avaliar habilidades por meio, por exemplo, da aplicação de uma prova prática, e a avaliação de aspectos mais subjetivos como atitudes e comportamentos. Outro tópico importante mencionado foi a necessidade 
de melhoria no departamento de recursos humanos das organizações públicas, no sentido de definir exatamente as necessidades de cada setor e o perfil do cargo, para que se possa escolher realmente o melhor candidato, sendo fundamental uma articulação e um planejamento nos editais dos concursos, visando a uma maior aproximação com a realidade das atribuições desses cargos.

Por fim, registra-se que parte das propostas de aperfeiçoamento e outras ponderações apresentadas dependem apenas de engajamento político para sua aplicabilidade. Uma legislação que regulamente todo o processo dos concursos públicos, em nível nacional, poderá contribuir para suprir lacunas existentes, algumas delas já descritas neste trabalho. É imprescindível que os princípios constitucionais da Administração Pública sejam devidamente atendidos no que tange aos processos seletivos públicos e que os servidores públicos, especialmente os que entraram recentemente para o quadro funcional, tenham consciência da importância de seu papel para a sociedade e para a melhoria da qualidade dos serviços que são prestados à população brasileira.

A realização da pesquisa com um grupo de servidores públicos já concursados pode ser considerada como uma limitação deste estudo, uma vez que tais sujeitos possuem uma visão de dentro do serviço público. Contudo, esse ponto possibilitou uma abrangência e riqueza das opiniões, indo além dos objetivos desta pesquisa, pois evidenciou problemas inerentes às organizações públicas e sua gestão de pessoal, que possuem reflexos posteriores aos processos seletivos.

Ademais, por tratar-se de um estudo de caso, as generalizações dos resultados são limitadas ao universo pesquisado. Dessa forma, sugere-se a realização de pesquisas futuras, com abordagem semelhante, que analisem as percepções de servidores de outras esferas governamentais, de estudantes de cursos preparatórios para concursos e de gestores públicos que participam do planejamento e da elaboração de certames públicos. Como possibilidade de pesquisas futuras, cita-se, ainda, outras discussões referentes ao universo dos concursos públicos e à gestão de pessoas no setor público, abordando, por exemplo, a implementação de legislação específica e aspectos referentes à estabilidade e à avaliação de desempenho.

\section{Referências}

1. ABRUCIO, L. F. Trajetória recente da gestão pública brasileira: um balanço crítico e a renovação da agenda de reformas. Revista de Administração Pública, São Paulo: FGV, Edição Especial Comemorativa, 2007.

2. ALBRECHT, P. A. T.; KRAWULSKI, E. Concurseiros e a busca por um emprego estável: reflexões sobre os motivos de ingresso no serviço público. Cadernos de Psicologia Social do Trabalho, v. 14, n. 2, p. 211-226, 2011.

3. AMARAL, H. K. Desenvolvimento de competências de servidores na administração pública brasileira. Revista do Serviço Público. Brasília, v. 57, n. 4, p. 549-563, 2006.

4. ANDRADE, T. W. C.; ALBUQUERQUE, P. H. M. Tomada de decisão usando o Analytic Hierarchy Process (AHP) para a seleção de um curso para concurso público. TAC, Rio de Janeiro, v. 2, n. 1, p. 19-32, 2012.

5. BARDIN, L. Análise de Conteúdo. Lisboa: Edições 70 LDA, 2010.

6. BORGES, M. C. M. Editais de concursos públicos e seus elementos padrões diante dos princípios constitucionais. Revista do Tribunal de Contas do Estado de Minas Gerais, v. 70, n. 1, 2009.

7. BRASIL. Constituição (1988). Constituição da República Federativa do Brasil. Brasília, DF: Senado Federal, 1988. 
8. Câmara da Reforma do Estado. Plano Diretor da Reforma do Aparelho do Estado. Brasília, DF, 1995.

9. Senado Federal. Projeto de Lei do Senado $n^{\circ} 74 / 2010$. Lei Geral dos Concursos. Disponível em: (http:// www.senado.gov.br/atividade/materia/ getPDF.asp? $\mathrm{t}=74640 \& \mathrm{tp}=1$ ).

10. BRESSER-PEREIRA, L. C. Administração pública gerencial: estratégia e estrutura para um novo Estado. Texto para discussão, 9. Brasília: ENAP, 1996.

11. CALDAS, I. L. D. A. Discussões acerca da avaliação periódica de desempenho do servidor público estável: Efeitos do princípio da eficiência sobre o desempenho dos recursos humanos na nova administração pública gerencial. Âmbito Jurídico, v. 89, p. 9540, 2011.

12. CARVALHO FILHO, J. S. Manual de Direito Administrativo. 27 ed. São Paulo: Atlas, 2014.

13. CAMÕES, M. R. S. et al. (Org.). Gestão de pessoas: bases teóricas e experiências no setor público. Brasília: ENAP, 2010.

14. CASTELAR, I. et al. Uma análise dos determinantes de desempenho em concurso público. Economia Aplicada, v. 14, n. 1, p. 81-98, 2010.

15. CUNHA, A. S.; CAVALCANTI, F. R. Recrutamento e seleção de pessoal: análise comparativa entre a iniciativa privada e a pública. Revista Espaço Acadêmico, n. 131, p. 76-80, 2012.

16. DI PIETRO, M. S. Z. Direito Administrativo. 27 ed. São Paulo: Atlas, 2014.

17. EVANS, P.; RAUCH, J. E. Bureaucracy and Growth: A Cross-National Analysis of the Effects of "Weberian" State Structures on Economic Growth. American Sociological Review, v. 64, n. 5, p.748-765, 1999.

18. FERRAREZI, E.; ZIMBRÃO, A.
Formação de carreiras para a gestão pública contemporânea: o caso dos Especialistas em Políticas Públicas e Gestão Governamental. Revista do Serviço Público. Brasília, v. 57, p. 63-86, 2006.

19. FOnTAinha, F. de C. et al. Processos seletivos para a contratação de servidores públicos: Brasil, o país dos concursos? Rio de Janeiro: FGV Direito Rio, 2014.

20. FONTAINHA, F. C. et al. O concurso público brasileiro e a ideologia concurseira. Revista Jurídica da Presidência, v. 16, n. 110, p. 671-702, 2015.

21. FREIRE, F. S. et al. Um Estudo das Exigências Programáticas em Contabilidade Pública nos Concursos Públicos Organizados pelo CESPE. Revista de Educação e Pesquisa em Contabilidade, Brasília, v. 6 , n. 4 , art. 5, p. 419433, 2012.

22. FREITAS, C. J. A Compreensão de texto em provas de Língua Portuguesa em concursos públicos. Dissertação de mestrado. 122 p. Programa de Pósgraduação em Letras, Recife: UFPE/ CAC, 2011.

23. LEAL, F. G.; SILVA, A. C. F.; DALMAU, M. B. L. Análise das Avaliações dos Concursos Públicos Realizados pelas IFES para o Cargo de Secretário -Executivo sob a Ótica da Gestão por Competência. Revista de Ciências da Administração, v. 16, n. 40, p. 191207, 2014.

24. MACHADO, E. M.; UMBELINO, L. M. A questão da estabilidade do servidor público no Brasil: perspectivas de flexibilização. Textos para discussão. Brasília: ENAP, 2001.

25. MATIAS-PEREIRA, J. Curso de Administração Pública: foco nas instituições e ações governamentais. 3 ed. São Paulo: Atlas, 2010.

26. MORGAN, D. L. Focus Groups as Qualitative Research. London: SAGE, 1997. 
27. MOTTA, F. Concurso Público: direito à nomeação e a existência de "cadastro de reserva". Revista Eletrônica sobre a Reforma do Estado (RERE), Salvador, Instituto Brasileiro de Direito Público, n. 24, 2011.

28. NASSUNO, M. Demissão por insuficiência de desempenho na reforma gerencial: avanços e desafios. Textos para discussão. Brasília: ENAP, 1998.

29. NOGUEIRA, B. O. S. P. Concurseiros: motivos e métodos para ingressar no serviço público. Dissertação (Mestrado em Sociologia) - Universidade de Brasília (UnB), Brasília, 2015.

30. NICOLAZZI, E. M. S. Crenças de servidores de uma universidade pública federal em relação à gestão de pessoas por competências. Navus - Revista de Gestão e Tecnologia. Florianópolis, SC, v. 3, n. 1, p. 20-30, 2013.

31. PAES DE PAULA, A. P. Administração Pública Brasileira entre o Gerencialismo e a Gestão Social. RAE (Impresso). São Paulo, v. 45, n. 1, p. 36-49, 2005.

32. SECCHI, L. Modelos organizacionais e reformas da administração pública. Revista de Administração Pública. Rio de Janeiro, v. 43, n. 2, p. 347-369, 2009.

33. SEVERINO, A. J. Metodologia do trabalho científico. 23. ed. São Paulo: Cortez, 2007.

34. TANIGUCHI, K.; ARTEN, K. C. S. $O$ paradigma da estabilidade do funcionário público federal frente ao princípio da eficiência. Revista de Direito, v. 13, n. 17, p. 73-88, 2010.

35. VIEIRA, M. M. F; ZOUAIN, D. M. (Org.). Pesquisa qualitativa em administração. Rio de Janeiro: Editora FGV, 2006. 